Check for updates

Cite this: RSC Adv., 2019, 9, 37919

Received 25th September 2019 Accepted 11th November 2019

DOI: $10.1039 / c 9 r a 08758 c$

rsc.li/rsc-advances

\section{Theoretical study of substituent effects on electride characteristics and the nonlinear optical properties of Liacalix[4]pyrrole $\uparrow$}

\author{
Hui Weng, ${ }^{a}$ Yunyang Teng, ${ }^{a}$ Qi Sheng, ${ }^{a}$ Zhongjun Zhou, DD *ab Xuri Huang, ${ }^{a}$ Zhiru Li ${ }^{a}$ \\ and Tao Zhang ${ }^{b}$
}

Electrides, a novel kind of ionic compound in which electrons serve as anions, have been proposed as potential second-order nonlinear optical (NLO) materials. In this work, the substituent effects on the electride characteristics and the NLO behaviour of Liacalix[4]pyrrole with an electride-like structure were studied theoretically. The results show that electron-donating and electron-withdrawing groups can effectively increase and decrease the first hyperpolarizability $\left(\beta_{0}\right)$, respectively, without affecting the electride characteristics (electron population). More interestingly, lithiation in which four $\mathrm{H}$ atoms bonded to $\mathrm{N}$ atoms are substituted by four Li atoms within the core structure of Liacalix[4]pyrrole remarkably improves the electride characteristics, with a large electron population of 0.74 e (1.02 e) at the NNA (ELF) basins, making this structure perhaps the first formal molecular electride with almost one electron isolated from the rest of the molecules. Furthermore, a relationship between the electride characteristics and the NLO properties is found: the more delocalization the excess electron of the electride experiences, the larger the $\beta_{0}$ value is. The present investigation may provide useful information for exploring high-performance second-order nonlinear optical materials based on organic electrides.

\section{Introduction}

During the past few decades, nonlinear optic (NLO) materials have made rapid progress in terms of both theoretical research and experimentation and have become an important component in the fields of optics and electricity. ${ }^{\mathbf{1 - 2 0}}$ With the research, design and improvement of new nonlinear optical materials, various methods for increasing nonlinear optical responses have been proposed. ${ }^{21-31}$

Electrides are a novel kind of ionic compound in which electrons serve as the anions. ${ }^{32-35}$ With such a unique structure, electrides show great potential in various applications, such as superconductivity, ${ }^{36,37}$ electronics, ${ }^{38-40}$ and catalysis. ${ }^{41-43}$ Recently, theoretical investigations by Li et al. have shown that systems in which the excess electrons are diffuse exhibit great NLO responses. Thereafter, a series of inorganic and organic molecular electrides were theoretically designed and studied by $\mathrm{Li}$ and co-workers, and the electride characteristics of these materials were identified by the highest occupied molecular orbitals. ${ }^{4-50}$ Among these materials, Li@calix[4]pyrrole is the most representative electride with a large NLO response. ${ }^{51}$ More

${ }^{a}$ Institute of Theoretical Chemistry, Jilin University, Changchun, 130023, People's Republic of China. E-mail: zjzhou@jlu.edu.cn

${ }^{b}$ College of Physics, Jilin University, Changchun, 130012, People's Republic of China $\dagger$ Electronic supplementary information (ESI) available. See DOI: 10.1039/c9ra08758c recently, Luis and Matito proposed four simultaneous criteria as necessary means to distinguish molecular electrides from similar species, namely, the existence of a non-nuclear attractor (NNA), an ELF basin, negative values of the Laplacian of the electron density, and NLO properties, which are very meaningful for identifying new molecular electrides. ${ }^{52-54}$ According to these criteria, Li@calix[4]pyrrole is accurately classified as an electride-like molecule because the electron number of NNA and ELF basins is far less than one electron. To the best of our knowledge, there is no formal molecular electride meeting all the above requirements except $\mathrm{Li}_{2} @ T C N Q$ and $\mathrm{Na}_{2} @ T C N Q$, in which the electride characteristics are considered to derive from $\mathrm{Li}_{2}$ and $\mathrm{Na}_{2}$. How do we construct a formal electride? Recently, the effects of substituents on the alkalide characteristics and NLO properties of $\mathrm{Li}^{+}$calix[4]pyrroleLi ${ }^{-}$, as an analogue of the electride of calix[4]pyrrole, have been reported theoretically. The authors demonstrate that electron-donating substituents can improve the alkalide characteristics of $\mathrm{Li}^{+}$(calix[4]pyrrole) $\mathrm{Li}^{-}{ }^{55}$ Then, can we obtain an formal electride with an isolated electron by means of the substituent effects based on Li@calix [4]pyrrole? With this question, we start this work. In the structure of calix[4]pyrrole, many different kinds of $\mathrm{H}$ atoms exist, such as $-\mathrm{CH},-\mathrm{CH}_{2}$, and $-\mathrm{NH}$, which can be substituted by electron-donating or electron-withdrawing groups. Many derivatives of calix[4]pyrrole with electron-donating or electronwithdrawing groups, such as methoxy $\left(-\mathrm{OCH}_{3}\right)$ and fluorine $(-\mathrm{F})$, have been synthesized, providing abundant structures for 
our present work. ${ }^{56}$ In addition to the conventional push-pull groups, lithiation by which $\mathrm{H}$ atoms in $-\mathrm{NH}$ groups are substituted by additional $\mathrm{Li}$ atoms is also used. In this work, we will pay attention to not only the substituent effect on the electride characteristic but also the substituent effects on the NLO properties, as well as the relationship between the electride characteristics and the NLO properties. The present investigation may provide useful information for exploring highperformance second-order nonlinear optical materials based on organic electrides.

\section{Computational methods}

The optimized geometric structures were obtained using the B3LYP method and 6-31+G(d) basis set in conjunction with the same thresholds as the article published by Luis and Matito (see ESI $\dagger) .{ }^{52}$ Frequency calculations were performed to confirm whether the obtained structures are real minima at the same level of theory.

For a large system, the $\mathrm{DFT}^{57,58}$ method is a good choice for calculating the first hyperpolarizability $\left(\beta_{0}\right)$ because it considers a balance between the efficiency and the computational cost. However, different functionals may yield different results for $\beta_{0}$, and thus, testing different functionals is necessary. Here, different functionals were used to calculate the $\beta_{0}$ value of Li@calix[4]pyrrole with a medium size. In this testing, CAMB3LYP $^{59,60}$ was chosen to calculate the $\beta_{0}$ and polarizability $\left(\alpha_{0}\right)$ value for all the systems in this work because the $\beta_{0}$ value (11 $876 \mathrm{au}$ ) of CAM-B3LYP is closest to that of MP2 (ref. 61) (11 $853 \mathrm{au}$ ) with the same mixed basis set where the 6$311++\mathrm{G}(3 \mathrm{df}, 3 \mathrm{pd})$ basis set is employed for $\mathrm{N}, \mathrm{Li}$ and the four $\mathrm{H}$ atoms of $-\mathrm{NH}$ groups and the $6-31+\mathrm{g}(\mathrm{d})$ basis set is used for other atoms. The results are shown in the ESI (Table S1†). The finite-field (FF) approach ${ }^{62-64}$ has been applied to evaluate the tensor components of the static hyperpolarizabilities. It simply requires the evaluation of the system energy for different amplitudes of the applied external electric field and can therefore be applied to a broad range of methods. When a system is in a weak and stable applied electric field, its energy can be written as:

$$
E=E^{0}-\mu_{\alpha} F_{\alpha}-\frac{1}{2} \alpha_{\alpha \beta} F_{\alpha} F_{\beta}-\frac{1}{6} \beta_{\alpha \beta \gamma} F_{\alpha} F_{\beta} F_{\gamma}
$$

where $E^{0}$ is the molecular energy without the electric field, and $F_{\alpha}$ is an electric field component along $\alpha$ direction; $\mu, \alpha_{\alpha \beta}$, and $\beta_{\alpha \beta \gamma}$ are the dipole moment, polarizability, and first hyperpolarizability, respectively. Moreover, the vertical ionization energy (VIE) and natural bond orbital (NBO) charge ${ }^{65}$ were obtained by the CAM-B3LYP and MP2 methods. Unless otherwise specified, the above mixed basis set was used for all calculations except geometry optimization. The excited states were calculated using the TD-CAM-B3LYP method. ${ }^{49,66-70}$

Topological analysis of electron density was performed using the MP2 method since Timerghazin and Peslherbe have shown that the characterization of excess electrons is sensitive to electron correlation and large basis sets. ${ }^{71}$ The topological analysis of atoms in molecules (AIM) ${ }^{72,73}$ and the electron localization function (ELF) ${ }^{74-76}$ were conducted by using the free and open source Multiwfn program. ${ }^{77}$

We used the following equations to calculate $\beta_{0}, \alpha_{0}$ and VIE.

$$
\begin{gathered}
\alpha_{0}=\frac{1}{3}\left(\alpha_{x x}+\alpha_{y y}+\alpha_{z z}\right) \\
\beta_{0}=\left(\beta_{x}^{2}+\beta_{y}{ }^{2}+\beta_{\mathrm{z}}{ }^{2}\right)^{1 / 2} \\
\beta_{i}=\beta_{i i i}+\beta_{i j j}+\beta_{i k k}, i, j, k=x, y, z \\
\mathrm{VIE}=E\left[\mathrm{M}^{+}\right]-E[\mathrm{M}]
\end{gathered}
$$

All calculations are performed using the Gaussian 09 program package. ${ }^{78}$

\section{Results and discussion}

\subsection{Topological analysis of electron density}

All optimized structures without imaginary frequencies are shown in Fig. 1. To facilitate the discussion, Li@calix[4]pyrrole is denoted as 1. All other structures are constructed based on this structure of $\mathbf{1}$. When eight $\mathrm{H}$ atoms at the $\beta$-positions of $\mathbf{1}$ are replaced with methoxy $\left(-\mathrm{OCH}_{3}\right)$ and fluorine $(-\mathrm{F})$ groups, octamethoxy-1 and octafluorine-1 are obtained, respectively. In addition, four $\mathrm{H}$ atoms within $\mathrm{NH}$ - groups of $\mathbf{1}$ are substituted by four Li atoms to form tetra-lithium-1. Except for octamethoxy-1, which has $\mathrm{C}_{1}$ symmetry, these complexes all have $C_{4 \mathrm{v}}$ symmetry.

3.1.1 The effects of electron-withdrawing and electrondonating substituents. 1 possesses a cup-like structure with a lithium atom near the centre of the $\mathrm{N}$-plane. As reported in the literature, under the action of four $\mathrm{N}$ atoms, the s valence electron of the $\mathrm{Li}$ atom is pushed out and becomes an excess electron at the bottom of the cup. ${ }^{51} 1$ can be described in the form of $\mathrm{Li}^{+}$(calix[4]pyrrole) $\mathrm{e}^{-}$, which was further verified by finding an NNA with a negative Laplacian value and an ELF basin below the -NH group, consistent with Luis' report. However, the electron numbers of the NNA and ELF basins are 0.47 and $0.91 \mathrm{e}$, respectively, at the MP2 level of theory, which are 0.3 and 0.4 e larger than those $(0.17$ and $0.51 \mathrm{e})$ at the B3LYP level of theory reported by Luis. The significant difference in these electron numbers can be attributed to the effects of electron correlation and the basis set. For octafluorine-1 with electron-withdrawing substituents $(-\mathrm{F})$, the electron numbers of NNA and ELF basins are 0.45 and 0.91 e, respectively, which are almost the same as those ( 0.47 and 0.91 e) of 1. For octamethoxy-1 with electron-donating substituents $\left(-\mathrm{OCH}_{3}\right)$, the electron numbers of NNA and ELF basins are also the same as those of octafluorine-1 (see Table 1 ). Why does the donating or withdrawing nature of the groups not change the electron population? By comparing the charges of these three molecules, it is found that the charges of the atoms near the excess electron are almost unchanged (see Table S2 $\dagger$ ), which results in the same electron population. Although the electron numbers of these complexes are unchanged by the presence of substituents, their integral volumes of the respective ELF 


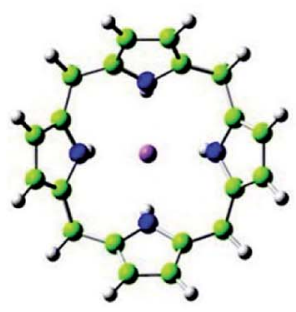

Top view

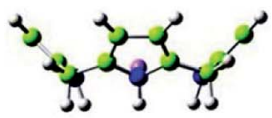

Side view

1
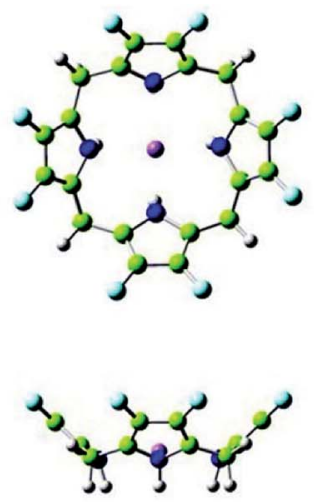

octafluorine-1
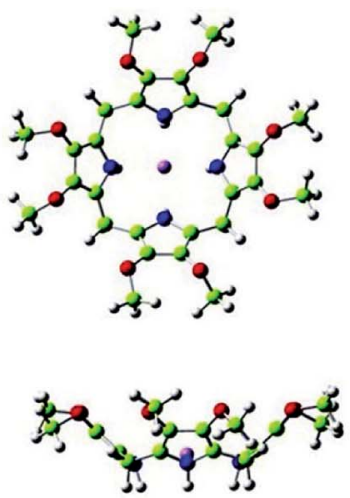

octamethoxy-1
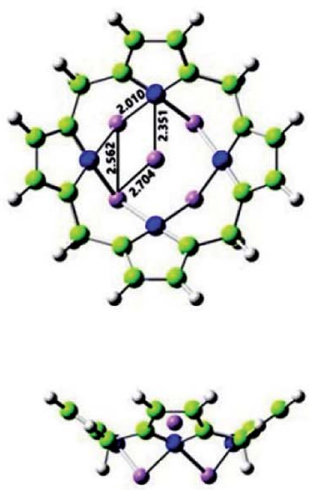

tetra-lithium-1

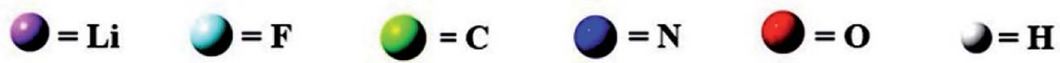

Fig. 1 Optimized structures of 1, octafluorine-1, octamethoxy-1, and tetra-lithium-1.

basins are obviously different. The order of integral volume is octafluorine-1 (7976) < 1 (8763) < octamethoxy-1 (13 079 bohr $\left.^{3}\right)$. Octafluorine-1, with electron-withdrawing substituents, has the smallest integral volume, while octamethoxy-1, with electron-donating substituents, has the largest integral volume, which indicates that the excess electron of octamethoxy-1 is more diffuse than that of octafluorine-1. The above analysis shows that the introduction of electron-donating or electron-withdrawing substituents does not change the electron population of electrides but significantly affects the diffusion of the excess electron, which may be an effective way to change the NLO properties while maintaining the electride characteristics. The NLO properties will be discussed in the following section.

3.1.2 The substituents of $\mathrm{Li}$ atoms (lithiation). As described in the above discussion, we found that the electrostatic field surrounding the excess electron plays an important role in the electron population. To break the original field, a new molecule was constructed, tetra-lithium-1, in which the four $\mathrm{H}$ atoms in the - $\mathrm{NH}$ groups of $\mathbf{1}$ were substituted by four $\mathrm{Li}$ atoms. Tetra-lithium-1 also has $C_{4 \mathrm{v}}$ symmetry, in which each $\mathrm{Li}$ atom is placed on the $\mathrm{N}-\mathrm{N}$ bridge. The $\mathrm{N}-\mathrm{Li}_{\text {in }}$ and $\mathrm{N}-\mathrm{Li}_{\text {out }}$ bond lengths are $2.351 \AA$ and $2.010 \AA$, respectively, and the $\mathrm{Li}_{\text {out }}-\mathrm{Li}_{\text {out }}$ and $\mathrm{Li}_{\text {out }}-\mathrm{Li}_{\text {in }}$ bond lengths are $2.562 \AA$ and $2.704 \AA$, respectively (see Fig. 1). Similar to 1 , an NNA with a negative Laplacian value and an ELF basin were also found in tetra-lithium-1 (see Fig. 2). Interestingly, the electron numbers of the NNA (ELF) basins further increased from 0.47 (0.91 e) of 1 to $0.74(1.02 \mathrm{e})$ in tetralithium-1. To the best of our knowledge, tetra-lithium-1 may be the first formal molecular electride with an isolated excess electron, except $\mathrm{Li}_{2} @ \mathrm{TCNQ}$ and $\mathrm{Na}_{2} @ \mathrm{TCNQ}$, in which the electride characteristics are considered to derive from $\mathrm{Li}_{2}$ and $\mathrm{Na}_{2}$. The large electron population of tetra-lithium- 1 can be understood by the NBO charges (see Table S3 $\uparrow$ ). Lithiation leads to charge transfer from $\mathrm{Li}$ atoms to $\mathrm{N}$ atoms, giving the $\mathrm{N}$ atoms of tetra-lithium-1 a more negative charge $(-0.904|e|)$ than that $(-0.693|e|)$ in 1 . This causes a higher percentage of the valence electron of the inner Li atom to be pushed out and captured by the cavity formed by the outer Li cations. The newly formed cavity of $\mathrm{Li}$ cations with a positive charge of $0.683|e|$ on each $\mathrm{Li}$ atom has a stronger ability to bind the excess electron than the previous cavity formed by $\mathrm{H}$ cations with a positive charge of $0.350|e|$. Moreover, compared to octafluorine-1 and octamethoxy-1, tetra-lithium-1 has the smallest integral volume of 5353 bohr $^{3}$. Tetra-lithium-1 has a larger electron number and a smaller integral volume, indicating that its excess electron should be more localized relative to the aforementioned three molecules.

Table 1 AIM and ELF data for electron density $\left(\rho\left(r_{\mathrm{c}}\right)\right)$, Laplacian of electron density $\left(\nabla^{2} \rho\left(r_{\mathrm{c}}\right)\right)$, basin population $(N($ pop), $N(\Omega))$, and basin volume at the nuclear critical point (NCP) of 1, octafluorine-1, octamethoxy-1, and tetra-lithium-1

\begin{tabular}{|c|c|c|c|c|c|c|c|}
\hline Chemical models & \multicolumn{4}{|l|}{ AIM } & \multicolumn{3}{|l|}{ ELF } \\
\hline Octafluorine-1 & NNA & 0.007 & -0.004 & 0.45 & C(NNA) & 0.91 & 7976 \\
\hline Octamethoxy-1 & NNA & 0.005 & -0.002 & 0.47 & C(NNA) & 0.91 & 13079 \\
\hline Tetra-lithium-1 & NNA & 0.010 & -0.009 & 0.74 & $\mathrm{C}(\mathrm{NNA})$ & 1.02 & 5353 \\
\hline
\end{tabular}




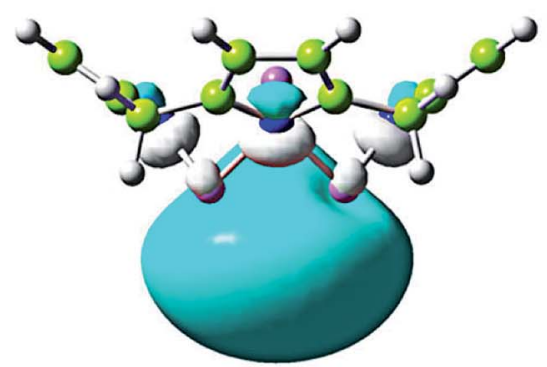

(a)

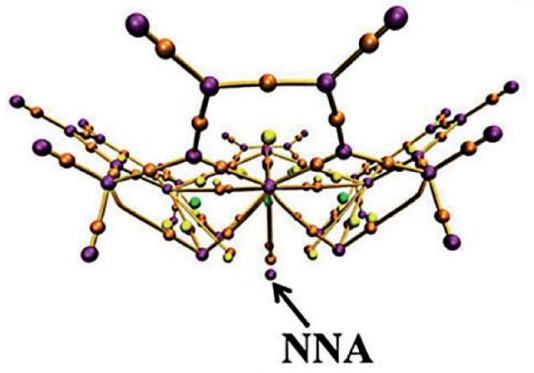

(b)

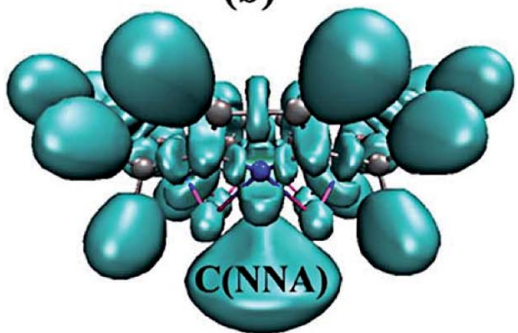

(d)

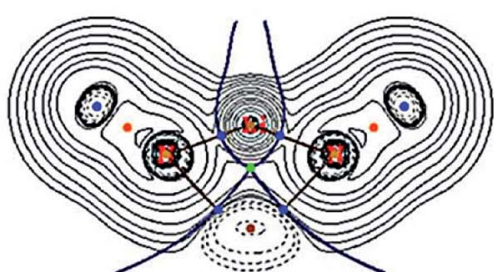

(c)

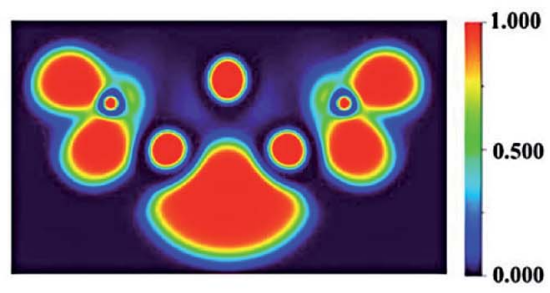

(e)

Fig. 2 (a) HOMO (isovalue $=0.02 \mathrm{au}$ ). (b) Non-nuclear attractor (NNA). (c) Two-dimensional (2D) plot of $\nabla^{2} \rho\left(r_{c}\right)$. (d) ELF isosurface image at a 0.800 value. (e) The colour-filled map of ELF for tetra-lithium-1.

\subsection{Nonlinear optical properties}

The NLO properties of $\mathbf{1}$, octafluorine- $\mathbf{1}$ and octamethoxy-1 have been calculated at the CAM-B3LYP level of theory, and the results are collected in Table 2 . Unlike the electron population, the first hyperpolarizabilities $\left(\beta_{0}\right)$ are very significantly affected by the substituents. When eight electron-withdrawing substituents (-F) is used, the $\beta_{0}$ value decreases from 11876 au (1) to 8977 au (octafluorine-1). However, when eight electrondonating substituents $\left(-\mathrm{OCH}_{3}\right)$ is used, the $\beta_{0}$ value is considerably increased from 11876 au (1) to 20562 au (octamethoxy1). For systems with electride or alkalide characteristics, a twolevel expression is often used to explain the $\beta_{0}$ value. ${ }^{79,80}$

Table 2 The first hyperpolarizability $\left(\beta_{0}\right.$, au), polarizability $\left(\alpha_{0}, \mathrm{au}\right)$, transition energies $\left(\Delta E\right.$, eV), oscillating strengths $\left(f_{0}\right)$, electronic configuration $\left(\mathrm{H}\right.$ is $\mathrm{HOMO}, \mathrm{L}$ is LUMO), HOMO energy $(\mathrm{eV})$, vertical ionization energy $(\mathrm{VIE}, \mathrm{eV})^{a}$ and $\mathrm{NBO}$ charges $(q,|e|)^{a}$ for octafluorine-1, 1, octamethoxy-1 and tetra-lithium-1

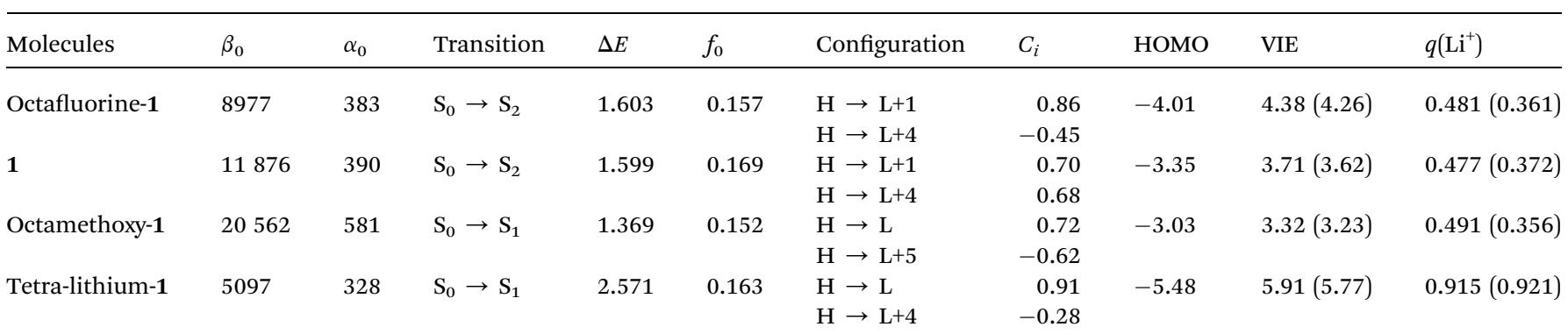

${ }^{a}$ The values outside parentheses were calculated at the CAM-B3LYP/6-31+g(d)/6-311++G(3df,3pd) level of theory. The values within parentheses were obtained at the MP2/6-31+g(d)/6-311++g(3df,3pd) level of theory. 


$$
\beta_{0} \propto \frac{\Delta \mu f_{0}}{\Delta E^{3}}
$$

where $\Delta E, f_{0}$ and $\Delta \mu$ are transition energy, oscillator strength and the difference in dipole moments between the ground state and crucial excited state. In the two-level expression, the third power of the transition energy $(\Delta E)$ is inversely proportional to the $\beta_{0}$ value; thus, the $\Delta E$ value is the decisive factor in the first hyperpolarizability. For the polarizabilities, from Table 2, the order of the $\alpha_{0}$ values is 383 (octafluorine-1) $<390(\mathbf{1})<581$ au (octamethoxy-1). The properties of the related excited state are calculated using the time-dependent CAM-B3LYP method, and the results are listed in Table 2. From Table 2, the order of $\Delta E$ is 1.369 (octamethoxy-1) $<1.599$ (1) $<1.603 \mathrm{eV}$ (octafluorine-1). The $\Delta E$ value is the difference in energy between the ground state and the excited state with a large oscillator. After FranckCondon excitation, octafluorine-1, 1, and octamethoxy-1 are excited into $\mathrm{S}_{2}, \mathrm{~S}_{2}$, and $\mathrm{S}_{1}$, respectively. All the electronic configurations in these excited states involved the excitation of the highest occupied molecular orbital (HOMO), which is the orbital containing the excess electron. When electron-donating substituents $\left(-\mathrm{OCH}_{3}\right)$ are used, the energy level of the HOMO is increased from -3.35 (1) to $-3.03 \mathrm{eV}$ (octamethoxy-1), which will lead to a small $\Delta E$. When electron-withdrawing substituents $(-\mathrm{F})$ are used, the energy level of the HOMO is decreased from -3.35 (1) to $-4.01 \mathrm{eV}$ (octafluorine-1), which leads to a large $\Delta E$. Moreover, the order of VIE is octafluorine-1 $(4.38 \mathrm{eV})>\mathbf{1}(3.71$ $\mathrm{eV})>$ octamethoxy-1 $(3.32 \mathrm{eV})$, consistent with the order of the HOMO energy levels. From the above analysis, we can conclude that the electron-withdrawing or electron-donating substituents cannot affect the electride characteristics but significantly affect the NLO behaviour.

Of the above three molecules, tetra-lithium-1 has the smallest $\beta_{0}$ and $\alpha_{0}$ value of 5097 and 328 au and the largest transition energy of $2.571 \mathrm{eV}$. The electronic configuration of tetra-lithium-1 is the HOMO $\rightarrow$ LUMO excitation. Due to lithiation, the energy level of the HOMO is considerably decreased from $-3.35 \mathrm{eV}(1)$ to $-5.48 \mathrm{eV}$ (tetra-lithium-1), leading to a large $\Delta E$. As usual, the VIE value of the molecular electride is smaller than that of alkali atoms, ranging from 5.4 to $3.9 \mathrm{eV}(\mathrm{Li}-$ Cs), ${ }^{81,82}$ and thus, sometimes, these molecules are called superalkalides. For example, the VIE values of octafluorine-1, 1, and octamethoxy-1 lie between 3.32 and $4.38 \mathrm{eV}$, which is less than that of Li. However, tetra-lithium-1 has a very large VIE value of $5.91 \mathrm{eV}$ at the CAM-B3LYP level of theory, which is greater than that of Li. From the above analysis, the following relationship is obtained: the more obvious the electride characteristic (the electron population), the larger the VIE value is. The large VIE value of tetra-lithium-1 may be attributed to the orbital of excess electron lowered by lithiation.

\section{Conclusion}

The effects of multiple substitutions on the electride characteristics and the second-order NLO properties $\left(\beta_{0}\right)$ of Li@calix[4]pyrrole (1) and its analogues (octafluorine-1, octamethoxy-1 and tetralithium-1) were theoretically studied at the CAM-B3LYP and MP2 levels of theory. Some conclusions are summarized as follows:
(1) Electron-donating and electron-withdrawing groups can effectively increase and decrease the first hyperpolarizability $\left(\beta_{0}\right)$, respectively, but do not damage the electride characteristics (electron population). For example, when all the $\mathrm{H}$ atoms at the $\beta$-positions of 1 were substituted by $-\mathrm{F}$ groups, the $\beta_{0}$ value was decreased from 11876 (1) to 8977 au (octafluorine-1), but when all the $\mathrm{H}$ atoms at the $\beta$-positions of 1 were substituted by $-\mathrm{OCH}_{3}$ groups, the $\beta_{0}$ value was substantially increased from 11876 (1) to 20562 au (octamethoxy-1). However, the electride characteristics were not changed, resulting in a nearly identical electron population (approximately $0.47 \mathrm{e}$ ).

(2) A different molecular electride, tetra-lithium-1, was successfully theoretically designed by lithiation in which four $\mathrm{H}$ atoms on $\mathrm{N}$ atoms were substituted by four Li atoms. Due to the large electron numbers of 0.74 and 1.02 e at the NNA and ELF basins, respectively, tetra-lithium-1 may be the first formal molecular electride with one isolated excess electron serving as an anion, except for $\mathrm{Li}_{2} @ \mathrm{TCNQ}$ and $\mathrm{Na}_{2}$ @TCNQ, in which the electride characteristics are considered to derive from $\mathrm{Li}_{2}$ and $\mathrm{Na}_{2}$. Furthermore, the vertical ionization energy of tetra-lithium-1 was $5.91 \mathrm{eV}$, which is larger than those (5.4$3.9 \mathrm{eV}$ ) of alkali atoms from Li to $\mathrm{Cs}$, indicating its higher stability. In addition, enhancement of the electride characteristics was accompanied by a decrease in the NLO properties.

\section{Conflicts of interest}

There are no conflicts to declare.

\section{Acknowledgements}

This work is financially supported by the China Postdoctoral Science Foundation (2015M571355).

\section{References}

1 B. J. Coe, Acc. Chem. Res., 2006, 39, 383-393.

2 J. A. Delaire and K. Nakatani, Chem. Rev., 2000, 100, 18171846.

3 S. H. Lee, J. R. Park, M. Y. Jeong, H. M. Kim, S. Li, J. Song, S. Ham, S. J. Jeon and B. R. Cho, ChemPhysChem, 2006, 7, 206-212.

4 C. G. Liu, W. Guan, P. Song, L. K. Yan and Z. M. Su, Inorg. Chem., 2009, 48, 6548-6554.

5 F. Meyers, S. Marder, B. Pierce and J. Bredas, J. Am. Chem. Soc., 1994, 116, 10703-10714.

6 S. Muhammad, H.-L. Xu, R.-L. Zhong, Z.-M. Su, A. G. AlSehemi and A. Irfan, J. Mater. Chem. C, 2013, 1, 5439.

7 P. C. Ray, Chem. Rev., 2010, 110, 5332-5365.

8 M. Schulz, S. Tretiak, V. Chernyak and S. Mukamel, J. Am. Chem. Soc., 2000, 122, 452-459.

9 T. G. Zhang, Y. Zhao, I. Asselberghs, A. Persoons, K. Clays and M. J. Therien, J. Am. Chem. Soc., 2005, 127, 9710-9720.

10 Z.-J. Zhou, G.-T. Yu, F. Ma, X.-R. Huang, Z.-J. Wu and Z.-R. Li, J. Mater. Chem. C, 2014, 2, 306-311. 
11 J. Wu, W. Wang, C. Gong, Q. Li, Z. Li, G. Deng, X. Zhang, K. Chen, Y. Gong and K. s. Chiang, J. Mater. Chem. C, 2017, 5, 7472-7478.

12 Q. Feng, Y. Li, G. Shi, L. Wang, W. Zhang, K. Li, H. Hou and Y. Song, J. Mater. Chem. C, 2016, 4, 8552-8558.

13 S. Muhammad, H. Xu, M. R. Janjua, Z. Su and M. Nadeem, Phys. Chem. Chem. Phys., 2010, 12, 4791-4799.

14 M. Schulze, M. Utecht, T. Moldt, D. Przyrembel, C. Gahl, M. Weinelt, P. Saalfrank and P. Tegeder, Phys. Chem. Chem. Phys., 2015, 17, 18079-18086.

15 C. Tonnele, B. Champagne, L. Muccioli and F. Castet, Phys. Chem. Chem. Phys., 2018, 20, 27658-27667.

16 A. Zhang, H. Xiao, C. Peng, S. Bo, H. Xu, M. Zhang, G. Deng, Z. Zhen and X. Liu, RSC Adv., 2014, 4, 65088-65097.

17 J. Dalal, N. Sinha, H. Yadav and B. Kumar, $R S C A d v ., 2015,5$, 57735-57748.

18 K. Nivetha, S. Kalainathan, M. Yamada, Y. Kondo and F. Hamada, RSC Adv., 2016, 6, 35977-35990.

19 S. Muhammad, A. R. Chaudhry, A. Irfan and A. G. Al-Sehemi, RSC Adv., 2017, 7, 36632-36643.

20 H.-L. Yu, W.-Y. Wang, B. Hong, Y.-L. Si, T.-L. Ma and R. Zheng, RSC Adv., 2017, 7, 41830-41837.

21 Y. Y. Liang, B. Li, X. Xu, F. Long Gu and C. Zhu, J. Comput. Chem., 2019, 40, 971-979.

22 S. Muhammad, H. Xu, Y. Liao, Y. Kan and Z. Su, J. Am. Chem. Soc., 2009, 131, 11833-11840.

23 M. Nakano, H. Fujita, M. Takahata and K. Yamaguchi, J. Am. Chem. Soc., 2002, 124, 9648-9655.

24 H. L. Xu, Z. R. Li, D. Wu, B. Q. Wang, Y. Li, F. L. Gu and Y. Aoki, J. Am. Chem. Soc., 2007, 129, 2967-2970.

25 G. Yu, X. Zhao, M. Niu, X. Huang, H. Zhang and W. Chen, J. Mater. Chem. C, 2013, 1, 3833.

26 R. L. Zhong, H. L. Xu, Z. M. Su, Z. R. Li, S. L. Sun and Y. Q. Qiu, ChemPhysChem, 2012, 13, 2349-2353.

27 Z. J. Zhou, X. P. Li, F. Ma, Z. B. Liu, Z. R. Li, X. R. Huang and C. C. Sun, Chem.-Eur. J., 2011, 17, 2414-2419.

28 C. Tu, G. Yu, G. Yang, X. Zhao, W. Chen, S. Li and X. Huang, Phys. Chem. Chem. Phys., 2014, 16, 1597-1606.

29 L. Chen, G. Yu, W. Chen, C. Tu, X. Zhao and X. Huang, Phys. Chem. Chem. Phys., 2014, 16, 10933-10942.

30 B. Li, C. Xu, X. Xu, C. Zhu and F. L. Gu, Phys. Chem. Chem. Phys., 2017, 19, 23951-23959.

31 F. Liu, Y. Yang, S. Cong, H. Wang, M. Zhang, S. Bo, J. Liu, Z. Zhen, X. Liu and L. Qiu, RSC Adv., 2014, 4, 5299152999.

32 W. Chen, Z. R. Li, D. Wu, R. Y. Li and C. C. Sun, J. Phys. Chem. $B$, 2005, 109, 601-608.

33 J. L. Dye, Inorg. Chem., 1997, 36, 3816-3826.

34 J. L. Dye, Acc. Chem. Res., 2009, 42, 1564-1572.

35 N. Ma, J. Gong, S. Li, J. Zhang, Y. Qiu and G. Zhang, Phys. Chem. Chem. Phys., 2017, 19, 2557-2566.

36 M. Miyakawa, S. W. Kim, M. Hirano, Y. Kohama, H. Kawaji, T. Atake, H. Ikegami, K. Kono and H. Hosono, J. Am. Chem. Soc., 2007, 129, 7270-7271.

37 K. Shimizu, H. Ishikawa, D. Takao, T. Yagi and K. Amaya, Nature, 2002, 419, 597.
38 S. Watanabe, T. Watanabe, K. Ito, N. Miyakawa, S. Ito, H. Hosono and S. Mikoshiba, Sci. Technol. Adv. Mater., 2016, 12, 034410.

39 H. Yanagi, K.-B. Kim, I. Koizumi, M. Kikuchi, H. Hiramatsu, M. Miyakawa, T. Kamiya, M. Hirano and H. Hosono, J. Phys. Chem. C, 2009, 113, 18379-18384.

40 X. Zhang, R. Guo, L. Jin, X. Dai and G. Liu, J. Mater. Chem. C, 2018, 6, 575-581.

41 M. Kitano, S. Kanbara, Y. Inoue, N. Kuganathan, P. V. Sushko, T. Yokoyama, M. Hara and H. Hosono, Nat. Commun., 2015, 6, 6731.

42 S. Zhao, E. Kan and Z. Li, Wiley Interdiscip. Rev.: Comput. Mol. Sci., 2016, 6, 430-440.

43 S. G. Dale and E. R. Johnson, Phys. Chem. Chem. Phys., 2016, 18, 27326-27335.

44 Y. Li, Z.-R. Li, D. Wu, R.-Y. Li, X.-Y. Hao and C.-C. Sun, J. Phys. Chem. B, 2004, 108, 3145-3148.

45 Z. Li, J. Yang, J. G. Hou and Q. Zhu, J. Am. Chem. Soc., 2003, 125, 6050-6051.

46 Z.-J. Li, Z.-R. Li, F.-F. Wang, C. Luo, F. Ma, D. Wu, Q. Wang and X.-R. Huang, J. Phys. Chem. A, 2009, 113, 2961-2966.

47 Z. R. Li, F. F. Wang, D. Wu, Y. Li, W. Chen, X. Y. Sun, F. L. Gu and Y. Aoki, J. Comput. Chem., 2006, 27, 986-993.

48 R. L. Zhong, H. L. Xu, Z. R. Li and Z. M. Su, J. Phys. Chem. Lett., 2015, 6, 612-619.

49 J.-J. Wang, Z.-J. Zhou, Y. Bai, Z.-B. Liu, Y. Li, D. Wu, W. Chen, Z.-R. Li and C.-C. Sun, J. Mater. Chem., 2012, 22, 9652.

50 Z. B. Liu, Z. J. Zhou, Y. Li, Z. R. Li, R. Wang, Q. Z. Li, Y. Li, F. Y. Jia, Y. F. Wang, Z. J. Li, J. B. Cheng and C. C. Sun, Phys. Chem. Chem. Phys., 2010, 12, 10562-10568.

51 W. Chen, Z. R. Li, D. Wu, Y. Li, C. C. Sun and F. L. Gu, J. Am. Chem. Soc., 2005, 127, 10977-10981.

52 V. Postils, M. Garcia-Borras, M. Sola, J. M. Luis and E. Matito, Chem. Commun., 2015, 51, 4865-4868.

53 O. El Bakouri, V. Postils, M. Garcia-Borras, M. Duran, J. M. Luis, S. Calvello, A. Soncini, E. Matito, F. Feixas and M. Sola, Chem.-Eur. J., 2018, 24, 9853-9859.

54 L. A. Burton, F. Ricci, W. Chen, G.-M. Rignanese and G. Hautier, Chem. Mater., 2018, 30, 7521-7526.

55 W. M. Sun, D. Wu, Y. Li and Z. R. Li, ChemPhysChem, 2013, 14, 408-416.

56 P. A. Gale, J. L. Sessler and V. Král, Chem. Commun., 1998, 18.

57 P. S. Liyanage, R. M. de Silva and K. M. N. de Silva, J. Mol. Struct.: THEOCHEM, 2003, 639, 195-201.

58 L. Yan, G. Yang, W. Guan, Z. Su and R. Wang, J. Phys. Chem. $B, 2005,109,22332-22336$.

59 Y. Tawada, T. Tsuneda, S. Yanagisawa, T. Yanai and K. Hirao, J. Chem. Phys., 2004, 120, 8425-8433.

60 T. Yanai, D. P. Tew and N. C. Handy, Chem. Phys. Lett., 2004, 393, 51-57.

61 C. Møller and M. S. Plesset, Phys. Rev., 1934, 46, 618-622.

62 J. Zyss, J. Chem. Phys., 1979, 70, 3333-3340.

63 J. Zyss, J. Chem. Phys., 1979, 70, 3341-3349.

64 J. Zyss, J. Chem. Phys., 1979, 71, 909-916.

65 A. E. Reed, R. B. Weinstock and F. Weinhold, J. Chem. Phys., 1985, 83, 735-746. 
66 K. Okuno, Y. Shigeta, R. Kishi, H. Miyasaka and M. Nakano, J. Photochem. Photobiol., A, 2012, 235, 29-34.

67 Y. Y. Hu, S. L. Sun, W. T. Tian, W. Q. Tian, H. L. Xu and Z. M. Su, ChemPhysChem, 2014, 15, 929-934.

68 H.-M. He, J. M. Luis, W.-H. Chen, D. Yu, Y. Li, D. Wu, W.-M. Sun and Z.-R. Li, J. Mater. Chem. C, 2019, 7, 645-653. 69 X. Li, J. Mater. Chem. C, 2018, 6, 7576-7583.

70 Y. Bai, Z. J. Zhou, J. J. Wang, Y. Li, D. Wu, W. Chen, Z. R. Li and C. C. Sun, J. Phys. Chem. A, 2013, 117, 2835-2843.

71 Q. K. Timerghazin, I. Rizvi and G. H. Peslherbe, J. Phys. Chem. A, 2011, 115, 13201-13209.

72 R. F. W. Bader, Atoms in Molecules: A Quantum Theory, Oxford University Press, New York, 1990.

73 R. F. Bader, Chem. Rev., 1991, 91, 893-928.

74 S. Grimme, J. Antony, S. Ehrlich and H. Krieg, J. Chem. Phys., 2010, 132, 154104.

75 B. Silvi and A. Savin, Nature, 1994, 371, 683.

76 A. D. Becke and K. E. Edgecombe, J. Chem. Phys., 1990, 92, 5397-5403.

77 T. Lu and F. Chen, J. Comput. Chem., 2012, 33, 580-592.

78 M. J. Frisch, G. W. Trucks, H. B. Schlegel, G. E. Scuseria, M. A. Robb, J. R. Cheeseman, G. Scalmani, V. Barone, B. Mennucci, G. A. Petersson, H. Nakatsuji, M. Caricato,
X. Li, H. P. Hratchian, A. F. Izmaylov, J. Bloino, G. Zheng, J. L. Sonnenberg, M. Hada, M. Ehara, K. Toyota, R. Fukuda, J. Hasegawa, M. Ishida, T. Nakajima, Y. Honda, O. Kitao, H. Nakai, T. Vreven, J. A. Montgomery Jr, J. E. Peralta, F. Ogliaro, M. Bearpark, J. J. Heyd, E. Brothers, K. N. Kudin, V. N. Staroverov, R. Kobayashi, J. Normand, K. Raghavachari, A. Rendell, J. C. Burant, S. S. Iyengar, J. Tomasi, M. Cossi, N. Rega, J. M. Millam, M. Klene, J. E. Knox, J. B. Cross, V. Bakken, C. Adamo, J. Jaramillo, R. Gomperts, R. E. Stratmann, O. Yazyev, A. J. Austin, R. Cammi, C. Pomelli, J. W. Ochterski, R. L. Martin, K. Morokuma, V. G. Zakrzewski, G. A. Voth, P. Salvador, J. J. Dannenberg, S. Dapprich, A. D. Daniels, O. Farkas, J. B. Foresman, J. V. Ortiz, J. Cioslowski and D. J. Fox, Gaussian 09, Revision D.01, Gaussian, Inc., Wallingford CT, 2016.

79 D. R. Kanis, M. A. Ratner and T. J. Marks, Chem. Rev., 1994, 94, 195-242.

80 J. L. Oudar and D. S. Chemla, J. Chem. Phys., 1977, 66, 26642668.

81 E. Zurek, J. Am. Chem. Soc., 2011, 133, 4829-4839.

82 W.-M. Sun, D. Wu, J. Kang, C.-Y. Li, J.-H. Chen, Y. Li and Z.-R. Li, J. Alloys Compd., 2018, 740, 400-405. 